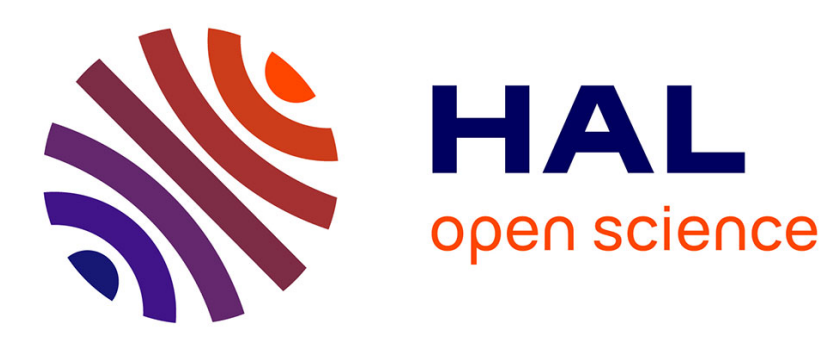

\title{
Towards a multimodal model of theorization processes
}

\author{
Mélodie Cartel, Sylvain Colombero, Eva Boxenbaum
}

\section{To cite this version:}

Mélodie Cartel, Sylvain Colombero, Eva Boxenbaum. Towards a multimodal model of theorization processes . Research in the Sociology of Organizations, 2017, Multimodality, Meaning, and Institutions, 54A, pp.153 - 182. 10.1108/s0733-558x2017000054a006 . hal-01675124

\section{HAL Id: hal-01675124 \\ http://hal.grenoble-em.com/hal-01675124}

Submitted on 4 Jan 2018

HAL is a multi-disciplinary open access archive for the deposit and dissemination of scientific research documents, whether they are published or not. The documents may come from teaching and research institutions in France or abroad, or from public or private research centers.
L'archive ouverte pluridisciplinaire HAL, est destinée au dépôt et à la diffusion de documents scientifiques de niveau recherche, publiés ou non, émanant des établissements d'enseignement et de recherche français ou étrangers, des laboratoires publics ou privés. 
Mélodie CARTEL \&

Sylvain COLOMBERO

Grenoble Ecole de Management

12 rue Pierre Sémard

38000 Grenoble, France

Email corresponding author: melodie.cartel@grenoble-em.com

\section{Eva BOXENBAUM}

MINES ParisTech - PSL Research University

60 Boulevard Saint-Michel

75272 Paris Cedex 06, France

$\&$

Copenhagen Business School

Kilevej 14A, 2000 Frederiksberg, Denmark 


\section{TOWARDS A MULTIMODAL MODEL OF THEORIZATION PROCESSES}

\section{Abstract}

This paper examines the role of multimodal rhetoric in processes of theorization. Empirically, we investigated the theorization process of a highly disruptive innovation in the history of architecture: reinforced concrete. Relying on archival data from a prominent French architectural journal in the period from 1885 to 1939, we studied the rhetorical modes at play in the theorization of reinforced concrete. First, we found that theorization entailed two recursive activities: dramatization and evaluation. While dramatization relies on both verbal and visual (i.e. multimodal) means, evaluation relies on verbal means. We integrated these components into a dynamic model of theorization that explains how visual discourse contributes to theorization beyond the effects of verbal discourse.

Key-words: Institutional innovation - Theorization - Multimodality 


\section{TOWARDS A MULTIMODAL MODEL OF THEORIZATION PROCESSES}

In order to gain momentum and become institutionalized, innovations must be theorized into logical models of cause and effect relationships that objectify their properties in an apparently irrefutable way (Greenwood, Suddaby \& Hinnings, 2002; Strang \& Meyer, 1993; Tolbert \& Zucker, 1996). The prominant approach to the analysis of theorization relies on a discursive perspective. In such a perspective, innovations may become institutionalized as a result of actors' rhetorical (verbal) work (Suddaby \& Greenwood, 2005) or of discursive rivalries, where new discourses challenge and replace existing ones (Phillips, Lawrence \& Hardy, 2004; Hardy \& Maguire, 2010). Regardless of the change mechanism they advocated, previous studies of theoretization focused exclusively on verbal discourse, ignoring the role of visual discourse in theorization processes. The neglect of visual discourse is potentially problematic in as much as the visual mode of communication offers considerable resources in the making and spreading of social meaning and its associated institutional effects (Meyer, Höllerer, Jancsary \& van Leeuwen, 2013). Most importantly, an exclusive focus on verbal discourses in theorization processes may lead scholars to overlook an important dimension of why theorization efforts succeed or fail. In an attempt to address this issue, we illuminated how multimodality, and more specifically the combination of verbal and visual modes, enables theorization processes.

In doing so, we followed recent calls for exploring the visual mode in organizational research (Meyer et al., 2013). Ray and Smith (2012) argue that "by collecting and analyzing data in the form of photographs, researchers can capture aspects of organizational reality without the distorting effects of other methods (e.g., recall bias) or when words alone are inadequate to capture the field experience" (p. 289). Photographs have been employed in organizational research as a data collection strategy aimed at eliciting richer responses from organizational members (Buchanan, 2001). They have also been used as a primary data source 
to access implicit organizational meanings of abstract concepts, such as corporate social responsibility (Höllerer, Jancsary, Meyer, \& Vettori, 2013). Photographs should be exploited much more in organization research (Buchanan, 2001), because they constitute a wide reservoir of data sources and as such, carry considerable potential to renew the direction of theory development (Buchanan \& Bryman, 2007, p. 483). Photographs and other static visual forms may, in the context of our study, help advance insights into theorization processes.

Empirically, we studied the theorization of reinforced concrete, a highly innovative building material in the late $19^{\text {th }}$ century, when it was first introduced to architecture. It was not until the 1930s that reinforced concrete became widely - and visibly - used to construct new buildings. Reinforced concrete was eventually accepted and adopted as the most appropriate construction material for modernist buildings, an architectural style that remained fashionable across the Western world until around 1970 (Jones, Maoret, Massa \& Svejenova, 2012). Contemporary architects and other construction professionals successfully theorized this new construction material in professional trade journals. In France, the theorization of reinforced concrete unfolded most vividly in Construction Moderne, an architectural trade journal that played a central role in the theorization of reinforced concrete in that country (Leniaud \& Bouvier, 2001). Articles in Construction Moderne relied on both verbal and visual communications to theorize reinforced concrete.

We make two contributions to the institutional literature on theorization. First, based on our findings, we identify two activities that operate recursively in the theorization of an innovation: dramatization and evaluation. Dramatization refers to actors' deliberate effort to showcase evidence for a causal chain in a particularly compelling manner. Dramatization, we argue, compels an audience to endorse certain sets of evidence that support a causal chain. Evaluation consists in producing a reliable judgment, either positive or negative, on the objective validity of the causal chain, thus serving a rational or technical purpose. Our 
empirical findings suggest the existence of a recursive relationship between dramatization and evaluation, which enhances the effectiveness of theorization relative to the use of only one of these activities.

Secondly, we suggest that the visual mode complements the verbal mode in terms of generating institutional effects from this recursive process. We found three multimodal startegies of dramatization, that build on essential properties of both visuals and verbal discourse: rhetorical strategies, narrative strategies and emotional strategies. Visuality has a well-established ability to readily engage audiences and to reinforce the factuality of claims (Höllerer et al., 2013), both essential to theorization. Based on our study, we propose that visual/verbal multimodality enhances the institutional effects of the theorization process. More specifically, we found that the visual representation of an innovation amplifies the effects of dramatization relative to the use of verbal representation alone. In contrast, we did not find visual representations to impact significantly on evaluation activities, which rested primarily on textual representations. Based on these findings, we elaborated a multimodal account of theorization processes that specifies the respective contributions of the visual and the verbal modes in these processes.

\section{THE ROLE OF THEORIZATION IN INSTITUTIONAL INNOVATION}

\section{Theorization and institutional innovation}

Theorization is a discursive process carried out by individual or organizational promoters of an innovation in order to support and accelerate the institutionalization of this innovation (Strang \& Meyer, 1993; Tolbert \& Zucker, 1996). Theorization is not a one-time act, but a process that is "integral to institutional change" and ceases only when full institutionalization is reached, or if the innovation collapses (Greenwood et al., 2002: 75; Munir, 2005). Indeed, as any mechanism aiming at producing social reality, theorization involves repeated enactment over long periods of time. Promoters develop theoretical accounts that capture 
desirable properties of the innovation into simplified cause-and-effect models (Strang \& Meyer, 1993). Theorization consists in generating causal chains that verbally establish logical relations between an innovation and its desirable effects. These causal chains objectify the innovation and render its benefits readily understandable for potential adopters (Mena \& Suddaby, 2016; Strang \& Soule, 1998; Tolbert \& Zucker, 1996).

Causal chains may be either pragmatic or normative in nature (Greenwood et al., 2002). Pragmatic causal chains emphasize the self-interested returns that the adoption of the innovation will deliver, the basis of legitimacy being rationality and efficiency (Tolbert \& Zucker, 1996). Cost-benefit analysis or similar devices may be mobilized to support such causal chains, which are expected to play an important role in settings where mimetic mechanisms of diffusion prevail, such as commercial settings (DiMaggo \& Powell, 1983; Greenwood et al., 2002). In contrast, normative causal chains arise from aligning the innovation with prevailing values and normative prescriptions, the basis for legitimacy being morality. Greenwood et al. (2002) offer an example of change in the accounting profession, where legitimacy was derived from alignment with the value of "client service", rather than from economic advantages. Such normative causal chains have been found to play an important role in processes of change in professionalized settings. Rather than appeal to functionalist outcomes, legitimation in such settings is likely to involve the demonstration of "professional appropriateness" (Greenwood et al., 2002).

The ability of promoters to develop causal chains depends upon the availability of empirical evidence to show how the innovation works and what desirable effects it produces (Tolbert \& Zucker, 1996). Among different sources of evidence to support theorization, exemplars have been found to be of particular interest (Nigam \& Ocasio, 2010). An exemplar is a concrete instantiation of an innovation that field actors mobilize to epitomize the innovation and its desirable effects (Jones \& Massa, 2013). In the architecture profession, 
architects may build an exemplary edifice to promote an innovation they value highly. In France, famous architects such as Le Corbusier and the Perret brothers built exemplary monuments in reinforced concrete to demonstrate the value of this building material. Nigam and Ocasio (2010) have shown that the promoters of an innovation use exemplars in theorization processes to illustrate a causal chain. Such seemingly objective representations constitute the basis for developing more abstract models.

\section{Theorization and multimodal discourse}

Our specific interest is in the multimodal means of discourse that the promoters of an innovation use to frame local exemplars into compelling, and generalizable causal chains. Innovation promoters formulate causal chains in verbal form to defend an innovation (Mena \& Suddaby, 2016; Suddaby \& Greenwood, 2005). When these causal chains become firmly associated with an innovation and gain acceptance among field actors, the innovation spreads and may gradually become institutionalized (DiMaggio \& Powell, 1983; Hardy \& Maguire, 2010; Phillips et al., 2004). When the causal chains themselves, or their association with an innovation, fail to convince the audience, the innovation stops diffusing and fades. Significant scholarly attention has been devoted to the verbal expression of causal chains that relate an innovation's properties to desirable effects (Harmon, Green \& Goodnight, 2015; Nigam \& Occasio, 2010; Suddaby \& Greenwood, 2005; Green, 2004). In contrast, other modes of communication, such as visuals, have received much less attention.

We embrace a multimodal perspective that considers visuals not as mere illustrations of verbal discourse, but as potential unique carriers of meaning (Kress \& van Leeuwen, 2001; Lefsrud, Graves \& Phillips, 2018; Meyer et al., 2013; Jancsary, Meyer, Höllerer \& Boxenbaum, 2018). According to this stream of literature, visuals carry meaning in a different way than verbal texts do. Their structure, including their organization (perspective, geometry) and their composition (which objects and subjects are present), plays an important role in the 
making of meaning (Kress \& van Leeuwen, 1996). As for unique abilities in meaning construction, "visualization, due to its fact-like character, is particularly suited to supporting the truth-claims of its authors (e.g., Graves, Flesher \& Jordan, 1996)" (Jancsary, Höllerer \& Meyer, 2016, p. 186). Previous research suggests that "the visual is capable of an accuracy and plenitude of description that verbal language cannot match /... [and that] visuals communicate with an immediacy of reception and a memorable impression of the essence of the message an essence that, in linear verbal texts, has to be assembled piece by piece over time" (Meyer et al., 2013, pp. 494-5). Accordingly, visuality constitutes a distinct and powerful mode through which actors express new ideas and imbue them with meaning.

We know little about the unique effects of the visual mode, as opposed to the verbal mode, when it comes to theorization processes (however, do see Meyer, Jancsary, Höllerer \& Boxenbaum, forthcoming for a theoretical elaboration). According to the multimodal literature, "processes of theorization ... are manifested not only in practices and verbal text but also in various visual artifacts./.... while both verbal and visual languages draw on the same fundamental systems of meaning that constitute our cultures, each does so by means of its own specific mode, and therefore requires different treatment in scholarly analysis" (Höllerer et al., 2013, pp. 143). It is plausible that charts and graphs may effectively relate the innovation to empirically observed effects (Tolbert \& Zucker, 1996), that drawings may be particularly helpful for showing how the innovation works, and that pictures may capture the effects of an innovation in a seemingly objective, and hence particularly convincing way. Given the paucity of knowledge on how visuals contribute to the establishment of causal chains in theorization processes, we pose the following research question: How do visuals contribute to the theorization of an innovation, and what is unique about their contribution relative to that of verbal text? 


\section{METHODS}

\section{The setting}

We studied theorization processes through an analysis of a highly innovative building material, reinforced concrete, in the field of French architecture. We trace theorization of reinforced concrete from 1885 to 1939 , which is the period just prior to its widespread diffusion after WWII (Boxenbaum \& Daudigeos, 2008). This time period is fruitful for two reasons. First, the theorization of reinforced concrete was intense during this period of time (Simonnet, 2005). Second, this period is analytically easy to trace in France, where scans of architecture journals are made available to the public via the online library of Cité de l'Architecture et du Patrimoine. Among the relevant trade journals, we chose Construction Moderne because it dedicated significant attention to reinforced concrete for decades (Leniaud \& Bouvier, 2001). Indeed, it promoted the implementation of reinforced concrete by highlighting the best building methods, stimulating architects' rationality and preventing the misuse of reinforced concrete. Construction Moderne is also relevant because it emphasized exemplary constructions, using both verbal and visual materials. Each article uses both verbal texts and visuals to support its main points and/or to describe exemplary constructions.

\section{Data collection and sampling}

We downloaded all issues of Construction Moderne from 1885 to 1939 and selected articles that focused on concrete, operationalized as at least five appearances of concrete in the article. This process yielded 531 articles, which we read before singling out 20 articles for in-depth analysis. Articles were selected according to two criteria. First, the building had to be framed as innovative in terms of how architects worked with reinforced concrete. Second, we selected exemplary buildings. If several articles treated the same exemplary building and/or the name of a building was reproduced, we judged the building to be exemplary. We also considered a building exemplary if it had been constructed by an influential architect (e.g., Pol 
Abraham or the Perret brothers). We used these criteria to reduce the selection to a final sample of 20 articles describing 12 exemplary buildings (see the list of exemplars in Table A1) which displayed an innovative use of reinforced concrete. To analyze the articles, we converted the .pdf files to .txt format and extracted the 20 articles in question, which we subsequently cleaned and associated with the original images from the .pdf files.

\section{Data analysis}

First, we created a sequence of events to provide further data analysis with a robust structure upon which to build (Langley, 1999). We ordered all the exemplars displayed in Construction Moderne chronologically along the sequence of events. Such time bracketing helped to organize the description of the theorization process in a logical and simple format (Langley \& Truax, 1994). We looked for related causes and effects that pertained to reinforced concrete and identified elements such as the stability, beauty, or flexibility of reinforced concrete. The sequence of events thus revealed three consecutive causal chains: (1) "constructions in reinforced concrete are more stable than constructions in stone"; (2) "constructions in reinforced concrete are esthetic"; and (3) "using reinforced concrete provides architects with flexibility." Table A2 indicates the time-related presence of these three causal chains.

Second, we coded the visuals and the verbal text of the 20 articles of our sample. To code the verbal text, we used an inductive/iterative methodology inspired by the verbal coding frameworks of Corbin and Strauss (2008) and Gioia, Corley and Hamilton (2012). To code the visual material, we followed methodological recommendations from visual semiotics (Höllerer et al., 2013; Jancsary et al., 2016; Jancsary et al., 2018). We coded each visual based on the three "metafunctions" of the visual mode: ideational, interpersonal and textual (Halliday, 1994). The ideational metafunction refers to "what is happening inside the picture." For each visual, we first examined who and/or what was represented in the pictures. We then 
distinguished between visuals according to the nature of action. Visuals can be narrative, when they infer a dynamic relationship between elements, or analytical, when they are static and depict details of an element, or symbolic, when the disposition of elements refers to specific meanings in the shared cultural repertoire (Jancsary et al., 2018). The interpersonal metafunction refers to the suggested relation between the viewer and the elements of the picture. Following Jancsary et al. (ibid), we coded for both the social distance inferred by the picture, i.e. whether the viewer is personally addressed or not, and the suggested power relations between the viewer and the elements of the visuals. The textual metafunction refers to the composition of the visual and whether or not certain elements are given more salience than others. We typically coded for perspectives and the visual's organization.

Our multimodal analysis aimed at identifying the theorization of reinforced concrete. In contrast to verbal language, pictures cannot easily communicate cause-effect relationships : "a photo of a fire and the smoke caused by it represents a cause-effect relationship, but the causality must be inferred by the viewer of the photo; there is no pictorial device which expresses it" (Nöth, 2011, p. 308). This feature prevents a purely visual semiotic analysis of theorization. To identify the role of visuals in theorization, we iterated between our verbal analysis (i.e. linguistic syntax) and our visual analysis (i.e. iconic syntax), taking into consideration also the production context of Construction Moderne. This multimodal iteration was necessarily exploratory and highly interpretive in nature.

Our verbal and visual codings, combined with our multimodal iterations, revealed two main activities at play in the theorization of reinforced concrete: dramatization and evaluation. Dramatization refers to the mise-en-scène of exemplary monuments. Construction Moderne dramatized the buildings and monuments displayed in its articles, emphasizing a specific characteristic, for instance, the beauty of the façade in Maison, 1 rue Danton. Particularly, we found three dramatization strategies that all involved both texts and 
visuals: rhetorical strategies, emotional strategies and narrative strategies. Rhetorical strategies refer to strategies previously identified in the institutional literature (Suddaby \& Greenwood, 2005). Rhetorical strategies use specific vocabulary (both textual and visual) to highlight causal chains, for instance, the display of a vocabulary of sobriety to emphasize the elegance and beauty of concrete. Narrative strategies consist in displaying causal chains by telling a story, for instance, organizing the visual visit of a building, explained by the text, to display the flexibility of reinforced concrete in organizing the whole building. Finally, emotional strategies consist in displaying texts and pictures that are supposedly provocative of a physical emotion to the reader. For instance, photographs displaying buildings from a low angle stress their stability, as the building from this angle exerts domination over the viewer (Jancsary et al., 2018). Evaluation refers to the statement of Construction Moderne as regards the success or failure of the exemplary monument to showcase a causal chain. Evaluation intellectualizes and generalizes the properties of reinforced concrete that were dramatized based on the exemplary monument. Here is an example of evaluation in Maison, 1 rue Danton: "We see here how the choice of this construction mode allowed the architect to enhance the yield of the land" (Construction Moderne, 1901(15): 328). While dramatization draws extensively on multimodal discourse, evaluation relies exclusively on verbal discourse.

\section{THEORIZING REINFORCED CONCRETE}

The theorization of reinforced concrete from 1885 to 1939 generated three causal chains consecutively: (1) "constructions in reinforced concrete are more stable than constructions in stone"; (2) "constructions in reinforced concrete are esthetic"; and (3) "reinforced concrete provides architects with flexibility."

\section{Causal chain 1 - Stability (1897 - 1912)}

From 1897 to 1912, Construction Moderne worked on the elaboration of causal chain (1) "constructions in reinforced concrete are more stable than constructions in stone." It took four 
cycles of dramatization and evaluation to consolidate this causal chain. Particularly, dramatization relied on two discursive strategies: a rhetorical strategy and an emotional strategy. The rhetorical strategy consisted in combining elements of vocabulary stemming from the same semantic field, here a technical semantic field. The emotional strategy consisted in provoking physical emotions in the viewer by displaying emotionally engaging visuals.

\section{Dramatization of Pont Alexandre III}

The dramatization of Pont Alexandre III in Construction Moderne built on a rhetorical strategy. Both the verbal text and visuals used a technical vocabulary. The written text reenacted the tense political context that urged architects to address an unprecedented technical challenge. Pont Alexandre III was built in Paris as a symbol of the Franco-Russian alliance formed in 1891 by Emperor Alexandre the Third and the French president, Sadi Carnot. In order to fill the symbol with life, the bridge had to meet technically challenging requirements. It had to be flat enough to enable people to see the Invalides from the Champs Elysées. The unbroken perspective would symbolize the friendship of Paris and Moscow. Because the surface of the bridge was to be flat, the structure of the arch would exert considerable downward pressure on the foundations of the bridge, the risk being that the foundations would be unable to bear such pressure. Such a technical challenge had never been solved before, making Pont Alexandre III an exemplary construction. Indeed, technical considerations had prompted the abandonment of the first attempt to build such a bridge in 1824. As shown in Figure 1, technical diagrams inserted in the verbal text reflected the construction's technicity.

Insert Fig.1 about here

\section{Dramatization of Maison, 1 rue Danton}

In the late 1890s, having patented the Hennebique System, François Hennebique, the father of reinforced concrete, set out to demonstrate the value of his construction system in the form 
of an exemplary building. Maison, 1 rue Danton was the first exemplary construction to use the Hennebique System as a unique construction system. It is located in Quartier Latin, one of the most central districts of Paris. To dramatize this theorization, Construction Moderne employed a rhetorical strategy similar to the one used for Pont Alexandre III. Both the visual and verbal texts highlighted the technical challenges that were overcome by using reinforced concrete:

"The construction site had the shape of a triangle. Its size was insufficient. In order to install all services and apartments, a standard masonry construction would have required a larger area. The land being very expensive, it was necessary to maximize the net usable area by any means possible. [...] The only option left was reinforced concrete, which had already been applied to several realizations, but had never been adopted as a unique construction system." (Construction Moderne, 1901(15): 328, our own translation from French)

\section{Dramatization of Eglise Saint-Jean de Montmartre}

Eglise Saint Jean de Montmartre was completed in 1904. It was the first religious building in France to be constructed of reinforced concrete. Construction Moderne relied on an emotional strategy to visually dramatize the stability of reinforced concrete in this exemplar. This strategy consisted in an angle of visual display that reinforced the powerfulness of the church building relative to the viewer. As shown in Figure 2, the picture is taken from a (relatively) low angle that makes the reader look up at a high vault. The photographic angle is not only intimidating, but overwhelms the reader with the empty volume under the vault, the display of which represents 80 percent of the picture.

Insert Figure 2 about here 


\section{Dramatization of the Royal Liver Building}

When it was completed in 1911, the Royal Liver Building was the tallest building ever built in Europe. The frame of the Royal Liver Building was constructed entirely of reinforced concrete, using the Hennebique System as a unique construction system. Its dramatization relied on an emotional strategy similar to that of Eglise Saint-Jean de Montmartre. The visual reproduction of the Royal Liver Building, depicted in Figure 3 below, made the front page of the journal issue. This picture of the building was taken from a relatively low angle, which reinforces the remarkable size of the building and its imposing qualities. The angle positions the viewer as small and powerless in relation to this giant structure, a visual effect that, through dramatization, reinforces the theorization of reinforced concrete as a stable building material.

\section{Insert Fig. 3 about here}

\section{Dramatization of Immeuble Ford}

L'immeuble Ford was inaugurated in 1929 as the symbol of the influence of Ford's commercial success in France. The focus of the article is the façade of the building. To display the strength of reinforced concrete in this building, Construction Moderne relies mainly on visuals. The dramatization technique is the same as for other buildings. It consists in taking the pictures from a (very) low angle, suggesting that the building is so strong that it exerts domination over the viewer (see Figure 4 below).

\section{Insert Figure 4 about here}

Other pictures add to this overall impression of power by displaying night panoramas of the building. At the depicted intersection, l'Immeuble Ford is the only building that has its lights switched on at night, suggesting its importance, opulence and wealth. While only the 
first picture dramatizes the strength of reinforced concrete, the other pictures add to its glory by displaying wealth, height and access to electricity.

\section{Evaluation of causal chain 1}

The evaluation of causal chain 1 consists in giving both particular and general statements on the stability of concrete. First, evaluation stresses the role of reinforced concrete as a solution to specific technical problems faced by the architect. For instance, the evaluation of causal chain 1 in the display of Eglise Saint-Jean de Montmartre goes as follows:

"Eglise Saint-Jean is a living proof of this statement [that reinforced concrete enable constructions that are stable, resistant and economic]. Since its finalization two years ago, the architect has found no reason to worry about the security of his system, regarding both its stability and protection from rain, snow, hot and cold." (Construction Moderne, 1905(15): 340, our own translation from French)

Second, evaluation generalized the role of reinforced concrete in any instances by comparing it with other techniques and materials. For instance, Construction Moderne refers to the Royal Liver Building as "the epitome of modern construction." The journal compares the Hennebique System to analogous systems used in the United States, which at that time was the world leader in building tall monuments:

"This enormous construction rests on a single monolithic frame made of reinforced concrete (Hennebique System,) the role of which is analogous to that of metal structures in huge American buildings." (Construction Moderne, 1912(25): p. 463, own translation from French)

Given the leadership of the United States in this area, this verbal statement is equivalent to endorsing the stability of reinforced concrete. 


\section{Causal chain 2 - Aesthetics (1901 - 1932)}

From 1901 to 1932, Construction Moderne made two attempts to theorize causal chain (2): "constructions in reinforced concrete are esthetic." Each attempt was characterized by an original dramatization strategy consisting of either a narrative strategy or a rhetorical strategy. The narrative strategy involved both verbal and visual texts displaying "stories." In the late 1920's, causal chain (2) gained a second wind through the elaboration of a new esthetic criterion, sobriety. Dramatization during this period rested upon a rhetorical strategy and the elaboration of a multimodal lexicon of sobriety, a qualification that would later come to define modern architecture.

\section{Dramatization (turn of century)}

Construction Moderne relied on a narrative strategy to dramatize the esthetic of the façade of Maison, 1 rue Danton.

An example of the narrative strategy may be found in the trade journal's display of Maison, 1 rue Danton. The first page of the journal's issue 1901(15) displayed a full-page drawing of the façade of the building (See Figure 5 below). This drawing is organized as a story instead of a static description. The drawing is composed of two elements. The first one is the visual reproduction of the façade. The second element is imaginative and represents two gentlemen in the street, perhaps architects, who are elegantly dressed and engaged in conversation, facing the façade. One of them carries a drawing board, suggesting that one is ready to sketch the façade. This mise-en-scène suggests that the originality of the building lies in its façade, which seems ordinary in comparison to traditional façades of this neighborhood. As such, the story is organized as an enigma: "Why is this ordinary, opulent façade worthy of special attention from architects?" The solution to the enigma was to be found in the verbal text of the article, which stated that the façade and its ornaments were built entirely of 
concrete. The traditional decoration of the façade was achieved by molding concrete, instead of carving ashlar.

Insert Fig.5 about here

\section{Dramatization (1929 - 1932)}

Construction Moderne used three exemplars to convey sobriety, a new esthetic criterion associated with constructions in reinforced concrete. To dramatize the esthetics of reinforced concrete in the exemplars, Construction Moderne relied on both visuals and verbal texts. The journal presented both interior and exterior images that highlighted the purity of shapes and volumes. The written texts also conveyed sobriety through plain, pure, and simple elements, which are associated with elegance, style, grace and distinction. Through sobriety, reinforced concrete was cast in a positive esthetic light.

Le Grand Hotel à Paris Plage was presented in Construction Moderne in 1929. It was the first exemplary edifice used to display and celebrate the sobriety of reinforced concrete. Most of the pictures and text revolved around two contiguous living rooms of the hotel, an octagonal living room which was described as being "particularly gracious", and a rectangular living room characterized by plain walls and large bay windows facing the ocean (see Figure 6). The photographic angles of these pictures were not neutral. They highlighted games of light and shadow through the windows, suggesting that the living rooms were designed in continuity with the outside, rather than as closed entities that carry their own esthetics. The sobriety of rooms, ceilings, walls and architectural volumes is in harmony with the exterior environment.

Insert Fig.6 about here

La Banque Nationale de Crédit à Nice was presented in Construction Moderne in 1929. The article and pictures revolved around the description of one single room: the great hall, which is the main entrance of the bank (see Figure 7 below). This room is very large, and the 
architectural style classical. The walls and pillars, made entirely of concrete, are sober. The esthetic effect of sobriety is reinforced by the minimalism of the furnishings.

\section{Insert Figure 7 about here}

L'Immeuble Ford was presented in Construction Moderne in 1931. Both the verbal and visual texts conveyed the esthetic qualities of the building's façade. The written text emphasized "the elegance of the building's shape", noting that "The Immeuble Ford is characterized by beautiful proportions and a nice silhouette." (Construction Moderne 1931(35): 762, own translation from French). The visuals displayed a sober façade shaped in a rather round silhouette (see Figure 8). According to Construction Moderne, the elegance of the building's silhouette, volumes, contours and proportions stemmed from the use of reinforced concrete in a unique structure.

\section{Insert Figure 8 about here}

\section{Evaluation}

Again, the evaluation took two forms: a specific form dedicated to evaluating the beauty of specific buildings, and a generalized form dedicated to stressing the overall validity of the causal chain. The following evaluation of Maison, 1 rue Danton illustrated the specific evaluation of the beauty of certain buildings. Construction Moderne suggested that the physical imitation of ashlar was convincing, whereas the color of concrete was problematic:

"As for the façade, the architect feared that the wall in reinforced concrete would seem dull and lifeless. A decoration in sandstone or painting or even graphite would have provided the façade with an amusing color. Nevertheless such decoration would have masked the concrete, which the owner wanted to stage. In any case, considering the grey aspect that stone acquires in Paris after some 
years, we may hope that concrete will behave, if no better, at least not worse." (La

Construction Moderne, 1901(16): p. 343, own translation from French).

An example of generalization of the evaluation of causal chain 2 may be found in the Grand Hôtel à Paris Plage. Sobriety was displayed in this issue as the trade mark of one particular iconic architect, Raoul Jourde, as a mark of generalizability:

"The room is of rare simplicity, [...] and rare beauty. This is Jourde!" (La Construction Moderne, 1929(20): 408, own translation from French).

These different examples show vividly that the esthetics of reinforced concrete changed from being questionable in 1901 in Maison, 1 rue Danton to becoming attractive around 1930. Sobriety became a symbol of elegance and modernism, as shown in the verbal texts that accompanied the three exemplars: le Grand Hôtel à Paris plage, la Banque Nationale de credit à Nice and l'immeuble Ford.

\section{Causal chain 3 - Flexibility (1929-1936)}

From 1929 to 1936, Construction Moderne worked on the elaboration of causal chain (3): "reinforced concrete provides architects with flexibility." The elaboration of this causal chain is characterized by a single dramatization strategy: a narrative strategy. The narrative strategy drew on sequences of visuals to allow the reader to experience an interactive tour of the buildings.

\section{Dramatization}

Construction Moderne dramatized the flexibility of reinforced concrete through two exemplary monuments: le Grand Hôtel à Paris plage and les villas d'Abraham. Through visual depiction, the journal dramatized reinforced concrete through a narrative strategy. Visual series were ordered in such a way as to take readers on a guided tour of the building. The first picture in the series usually presented the entrance of the building from afar, i.e. the view visitors would have when they first arrive. The series continued with pictures that were 
taken progressively closer to the building and presented its different façades, the entrance again and then the interior. In several series, Construction Moderne presented readers with architectural puzzles that invited readers to play a more important role in the dramatization of the exemplars. As shown in Figure 9, enigmas were presented to readers as they advanced from one picture to another. Plate 143 emphasizes large bay windows in the Grand Hotel à Paris Plage. While such large-sized bay windows are nowadays taken for granted, that was certainly not the case in 1929, when stone buildings with such windows would have collapsed. The enigma presented to initiated readers was: "How does the whole building stand?" The answer was provided in plate 144, which showed a pillar in a contiguous room; bay windows were made possible by placing a pillar in another room, which was not possible with constructions in stone. The accompanying text explains that this pillar may be placed anywhere in the building to provide support for the monolithic construction. When using reinforced concrete, therefore, architects have more spatial design flexibility (i.e. there is no need to have pillars in the living room, where they might appear bulky).

Insert Figure 9 about here

\section{Evaluation}

In 1932, Construction Moderne evaluated the flexibility of reinforced concrete, using the work of a famous architect, Auguste Perret. The journal designation of le Service Technique des Constructions Navales as an exemplar that serves both as illustration and demonstration of the architectural flexibility afforded by reinforced concrete. The evaluation of its flexibility drew mainly upon verbal text such as the following:

"The skeleton of the building is made of reinforced concrete. The space in between pillars and planks is filled with dividing walls made of light, mobile materials. These walls make it possible - and this is an interesting property - to undo the interior arrangements and replace them with other arrangements, such 
as to enlarge windows, create new ones or do away with them, all of it without consequence for the overall stability of the building." (La Construction Moderne 1932(40):14; own translation from French)

In endorsing the architectural flexibility of reinforced concrete, the verbal text framed reinforced concrete as a material that brings architecture back to the people, in contrast to previous construction movements that had done the opposite.

Finally, the retrospective showed how three causal chains related to the quality of reinforced concrete (stability, esthetics and flexibility) were constructed verbally and visually over a period of fifty years.

\section{DISCUSSION}

\section{Summary of findings}

Our multimodal analysis of how reinforced concrete was theorized in a French trade journal revealed the consecutive elaboration of three causal chains. Each one emphasized a particular quality of reinforced concrete as a building material: stability, aesthetics, and architectural flexibility. Collectively, they represent the theorization of reinforced concrete as a new construction material.

Our analysis uncovered two activities involved in theorization process: dramatization and evaluation. They unfolded simultaneously in each of the three causal chains, and were expressed verbally as well as visually. Figure 10 depicts these two activities and the respective roles of verbal and visual text in each activity. In our study, visuals played a predominant role in dramatization, and evaluation drew exclusively on verbal text. In the sections below, we elaborate on how dramatization and evaluation respectively enable the elaboration of causal relations in the process of theorization.

Insert Figure 10 about here 


\section{The role of dramatization in theorization}

Dramatization refers to the activity whereby the promoters of an innovation showcase empirical evidence to engage targeted audiences in supporting a causal chain. Early studies on theorization suggested that promoters of an innovation collect empirical evidence of its ability to produce more desirable effects than traditional methods do (Tolbert \& Zucker, 1996).

We have extended this perspective with a performative aspect: when the promoters of an innovation engage in dramatization, they present evidence for a causal chain in such a way that (1) the meaning is immediate and obvious to the targeted audience; (2) the display is spectacular enough to compel the targeted audience to engage with it. For instance, when architects want to promote an architectural innovation, they create a building to make their point. However, such buildings do not constitute exemplars per se; they must be dramatized to achieve the status of exemplarity. Buildings must be framed as spectacular in some way, such as being the tallest monument or the most technically challenging building ever built. Construction Moderne did so, for instance, when framing The Royal Liver Building as the tallest structure ever built in Europe or Maison, 1 rue Danton as an exact concrete replica of an elaborate stone-made façade. Dramatization turns buildings into exemplary monuments through immediate and compelling communication.

The immediacy and compelling effects were achieved primarily through visual communication. Compared to verbal texts, visuals provide the audience with a simplified and immediate understanding and readily engage the audience emotionally (Meyer et al., 2013). In combination with verbal texts, visuals are even more powerful in compelling audiences to engage with new causal chains. We identified three multimodal strategies that made causal chains compelling to the audience: rhetorical, emotional and narrative. In the rhetorical strategy, the reader is overwhelmed with a hyper-specific vocabulary. For instance, the display of "sobriety" in causal chain (2) bombs the reader with redundant visual and textual 
synonyms of sobriety. This vocabulary is then presented as crucial to the esthetics of reinforced concrete. In such a strategy, the verbal and visual texts are redundant. The visual text displays plain concrete walls and pure shapes, while the verbal text highlights the qualities of sobriety such as elegance and refinement. In the emotional strategy, the audience is prompted to experience specific emotions. This was the case when Construction Moderne displayed visuals that prompted the audience to feel dominated by the building (e.g., Figure 4). This emotional effect resulted from a low angle of photography that compels viewers to look up at an imposing building. The narrative strategy engaged the audience in a sensemaking journey. For instance, the sequence of visuals displayed in Le Grand Hôtel à Paris Plage immersed the audience in a guided tour of the hotel. Not only are readers visiting, they are also presented visual enigmas, the answers to which may be found in the verbal text.

\section{The role of evaluation in theorization}

Evaluation refers to the assessment of a causal chain as being objectively valid. The activity of evaluation seeks to validate the causal claims that are advanced in relation to an innovation. Promoters of the innovation assess and display objective support for the causal chains they advance and, in so doing, they reinforce the validity of the causal chain. In our empirical study, the authors in Construction Moderne drew support from the Royal Liver Building to establish that reinforced concrete was stable. This material enabled architects to build taller monuments than they could have done with stone. The journal provided further evidence for the stability of reinforced concrete by comparing it to similar initiatives in the United States of America, a country recognized at the time for its outstanding ability to erect tall monuments.

The activity of evaluation has traditionally been associated with the notion of justification in the institutional literature (Greenwood et al., 2002; Suddaby \& Greenwood, 2005). However, a previous study that was also conducted in a mature field with a high density of 
professionals found that the rational demonstration of an innovation's superiority compared to existing patterns was less central to theorization than was the moral alignment of an innovation with professional values (Greenwood et al., 2002). Our study contradicts this finding, suggesting that the demonstration of superiority was core to the act of theorization.

Our findings further suggest that evaluation operated almost exclusively through verbal text. Visuals may have helped establish the facticity of a particular building, but the particular elements under evaluation appeared only in the verbal text. It may well be that visual depiction of buildings is ill-suited for evaluation activities, beyond their ability to illustrate. It is possible that the material building influenced evaluation activities at the time, for instance in demonstrating stability. However, we did not consider material expression in this study and hence cannot draw conclusions about the role of this mode in theorization processes. Future research should definitely include materiality in studies of theorization.

\section{Contributions to theorization}

Previous works suggest that theorization is an on-going process aimed at objectifying the properties of an innovation (Greenwood et al., 2002; Munir, 2005; Smets, Morris \& Greenwood, 2012). Our study supports this claim and adds subjectification as an important, yet overlooked component of theorization. Subjectification refers to audiences engaging emotionally with the innovation and experiencing it as relevant and meaningful. Our study suggests that the activity of evaluation, expressed mostly in verbal text, is particularly wellsuited for objectifying the properties of an innovation. As importantly, the activity of dramatization, expressed mostly through visual means, compels the targeted audience to engage subjectively with new causal chains. Both activities are central to theorization processes, we argue, and complementary to one another.

We did not explicitly analyze the relationship between dramatization and evaluation in this study. Our findings show that they occur simultaneously, and we suggest that they may be 
necessary and collectively sufficient for theorization. Future studies should investigate whether they are recursively related in the sense of actively supporting or reinforcing each other or achieve a similar outcome if used consecutively.

\section{Contributions to multimodality}

The most significant contribution of our study to multimodality pertains to the notion of dramatization and its role in theorization processes. Our conceptualization of dramatization helps shed light on how different modes of communication contribute to establishing causal chains and engaging audiences in them. Greenwood and Suddaby (2005) proposed that the use of persuasive verbal rhetoric is central to legitimizing institutional change. Verbal rhetoric influences theorization processes, they argue, through narratives that resonate with deeply embedded values of the targeted audiences. Our paper extends this line of work to visual rhetoric. We suggest that visual rhetoric also compels audiences to engage with, and adopt, the causal chain that is being advanced as a justification for the adoption of an innovation. Visual rhetoric, we argue, is expressed as dramatization and, as such, it complements verbal rhetoric. The engaging features of verbal rhetoric, expressed in narrative form, is enhanced when dramatization is added through visual rhetoric. Our study suggests that verbal rhetoric and visual rhetoric reinforce each other in the form of multimodal strategies.

We identified three multimodal strategies in our case study: rhetorical, emotional and narrative. All three engage the reader in the theorization process, and draw on both verbal and visual discourse. Rhetorical strategies overwhelm the reader with the problem-solving aspects of the causal chain; emotional strategies evoke a positive affective response in the reader and associate this affect with the causal chain; narrative strategies invite the reader to engage in a sensemaking process that sustains the causal chain. 


\section{Further research}

Our research opens some exciting directions for further research on multimodality. Although we only engaged with visual and textual data, we recognize that material artifacts themselves (as opposed to their visual representation) may play an important role in evaluation activities in as much as they permit audiences to test an innovation before assessing it. Future research could also examine the unique role of the material mode in the recursive processes of theorization. 


\section{ACKNOWLEDGEMENTS}

This paper benefitted greatly from discussions at "The 2nd International conference on Visuality, Materiality, Multimodality", held in the Copenhagen Business School on 22-23 September 2016. We also gratefully acknowledge financial support from the Danish Council for Independent Research: DFF-1327-00030. 


\section{REFERENCES}

Boxenbaum, E. \& Daudigeos, T. (2008). Institutional factors in market creation: Concrete theorization of a new construction technology. Best Paper Proceedings of the 2008 Academy of Management Annual Meeting.

Buchanan, D. (2001). The role of photography in organization research: A reengineering case illustration. Journal of Management Inquiry, 10: 151-164.

Buchanan, D. \& Bryman, A. (2007). Contextualizing methods choice in organizational research. Organizational Research Methods, 10: 483-501.

Corbin, J.M. \& Strauss, A.L. (2008). Basics of qualitative research: techniques and procedures for developing grounded theory. 3rd ed. Sage: Newbury Park.

DiMaggio, P.J. \& Powell, W.W. (1983). The iron cage revisited: Institutional isomorphism and collective rationality in organizational fields. American Sociological Review, 48, 147-160.

Gioia, D.A., Corley, K.G. \& Hamilton, A.L. (2012). Seeking Qualitative Rigor in Inductive Research: Notes on the Gioia Methodology. Organizational Research Methods, 16(1), 15-31.

Graves, O.F., Flesher, D.L. \& Jordan, R.E. (1996). Pictures and the bottom line: The television epistemology of U.S. annual reports. Accounting, Organizations and Society, 21(1), 57-88.

Green, S. (2004). A rhetorical theory of diffusion. Academy of Management Review, 29: 653-669.

Greenwood, R., Suddaby, R. \& Hinings, C. R. (2002). Theorizing change: The role of professional associations in the transformation of institutionalized fields. Academy of Management Journal, $45(1), 58-80$.

Halliday, M. (1994). An introduction to functional grammar (2nd ed.). London: Edward Arnold.

Hardy, C. \& Maguire, S. (2010). Discourse, field-configuring events, and change in organizations and institutional fields: Narratives of DDT and the Stockholm convention. Academy of Management Journal, 53(6), 1365-1392.

Harmon, D., Green, S. \& Goodnight, G. (2015). A model of rhetorical legitimation: The structure of communication and cognition underlying institutional maintenance and change. Academy of Management Review, 40(1), 76-95. 
Höllerer, M., Jancsary, D., Meyer, R. \& Vettori, O. (2013). Imageries of corporate social responsibility: visual recontextualization and field-level meaning. In M. Lounsbury, \& E. Boxenbaum (Eds.) Institutional Logics in Action (39:139-174). Bingley: Emerald Group Publishing Part A (Research in the Sociology of Organizations).

Jancsary, D., Höllerer, M. \& Meyer, R. (2016). Critical analysis of visual and multimodal texts. In M. Wodak, and M. Meyer (Eds.) Methods of critical discourse studies: 180-204. London: Sage Publications.

Jancsary, D., Meyer, R. E., Höllerer, M. A., \& Boxenbaum, E. (2018). Institutions as multimodal accomplishments: Towards the analysis of visual registers. Research in the Sociology of Organizations, 54A, 87-117.

Jones, C., Maoret, M., Massa, F.G. \& Svejenova, S. (2012). Rebels with a cause: Formation, contestation and expansion of the de novo category "modern architecture", 1870-1975. Organization Science, 23(6), 1523-1545.

Jones, C. \& Massa, F.G. (2013). From Novel Practice to Consecrated Exemplar: Unity Temple as a Case of Institutional Evangelizing. Organization Studies, 34(8) : 1099-1136.

Kress, G. \& van Leeuwen, T. (1996). Reading images: The grammar of visual design. London: Routledge.

Kress, G. \& van Leeuwen, T. (2001). Multimodal discourse: The modes and media of contemporary communication. London: Hodder Education.

Langley, A. (1999). Strategies for theorizing from process data. Academy of Management Review, 24 (4), 691-710.

Langley, A. \& Truax, J. (1994). A process study of new technology adoption in smaller manufacturing firms. Journal of Management Studies, 31, 619-652.

Lefsrud, L. M., Graves, H., \& Phillips, N. (2018). Dirty oil or ethical oil? Visual rhetoric in legitimation struggles. Research in the Sociology of Organizations, 54 B, 101-142.

Leniaud, J.-M. \& Bouvier, B. (2001). Les Périodiques d'Architecture, XVIIIe-XXe siècle, Recherche d'une méthode critique d'analyse : Journée d'étude du 2 juin 2000 organisée au Collège de France. Etudes et rencontres de l'Ecole des Chartes. Paris : Ecole des Chartes. 
Mena, S. \& Suddaby, R. (2016). Theorization as institutional work: The dynamics of roles and practices. Human Relations, 69(8), pp. 1669-1708.

Meyer, R., Höllerer, M., Jancsary, D. \& van Leeuwen, T. (2013). The Visual Dimension in Organizing, Organization, and Organization Research Core Ideas, Current Developments, and Promising Avenues. Academy of Management Annals, 7(1): 487-553.

Meyer, R., Jancsary, D., Höllerer, M. \& Boxenbaum, E. (2017). The role of verbal and visual text in the process of institutionalization. Academy of Management Review. DOI:10.5465/amr.2014.0301

Munir, K.A. (2005). The social construction of events: a study of institutional change in the photographic field. Organization Studies, 26(1): 93 - 113.

Nigam, A. \& Occasio, W. (2010). Event Attention, Environmental Sensemaking, and Change in Institutional Logics: An Inductive Analysis of the Effects of Public Attention to Clinton's Health Care Reform Initiative. Organization Science, 21(4): 823-841.

Nöth, W. (2011). Visual semiotics: Key features and an application to picture ads. In E. Margaulis \& L. Pauwel (Eds.), The Sage handbook of visual research methods (pp. 298-316). London: Sage.

Phillips, N., Lawrence,T. \& Hardy, C. (2004). Discourse and institutions. Academy of Management Review, 29(4): 635-652.

Ray, J.L. \& Smith, A.D. (2012). Using photographs to research organizations: evidence, considerations, and applications in a field study. Organizational Research Methods, 15(2), 288315.

Simonnet, C. (2005). Le béton, histoire d'un matériau: Economie, technique, architecture. Editions Parenthèses : Marseille, France.

Smets, M., Morris, T. \& Greenwood, R. (2012). From practice to field: a multilevel model of practice driven institutional change. Academy of Management Journal, 55(4), 877-904.

Strang, D., \& Meyer, J. W. (1993). Institutional conditions for diffusion. Theory and Society, 22 (4), 487-511.

Strang, D., \& Soule, S. (1998). Diffusion in organizations and social movements: From hybrid corn to poison pills. Annual Review of Sociology, 24, 265-290. 
Suddaby, R., \& Greenwood, R. (2005). Rhetorical strategies of legitimacy. Administrative Science Quarterly, 50 (1), 35-67.

Tolbert, P. S., \& Zucker, L.G. (1996). The institutionalization of institutional theory. In S. Clegg, C. Hardy, \& W. R. Nord. (Eds.), The SAGE handbook of organization studies: 175-190. Thousand Oaks, CA: Sage Publications. 


\section{TABLES \& FIGURES}

FIG. 1

Pressurized Caisson (Pont Alexandre III)

Source : La Construction Moderne 1887(35), page 571

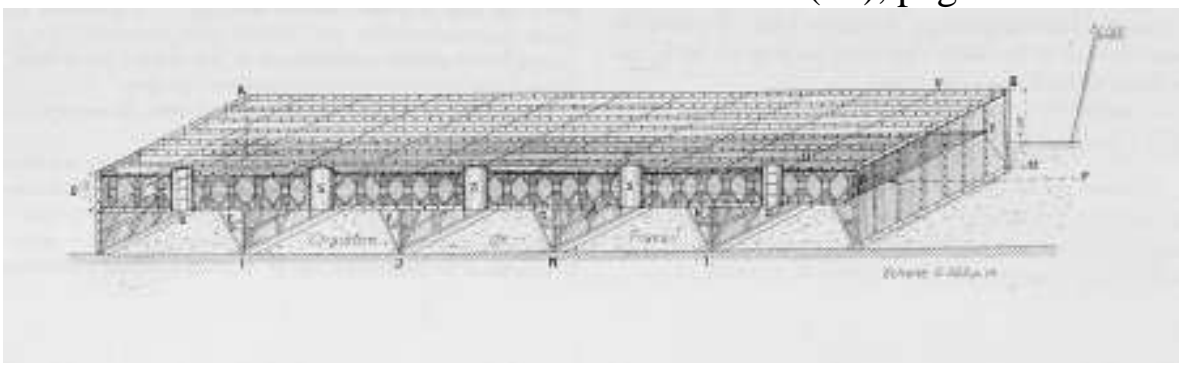


FIG. 2

Eglise Saint-Jean de Montmartre

Source : La Construction Moderne 1905(15), plate 58

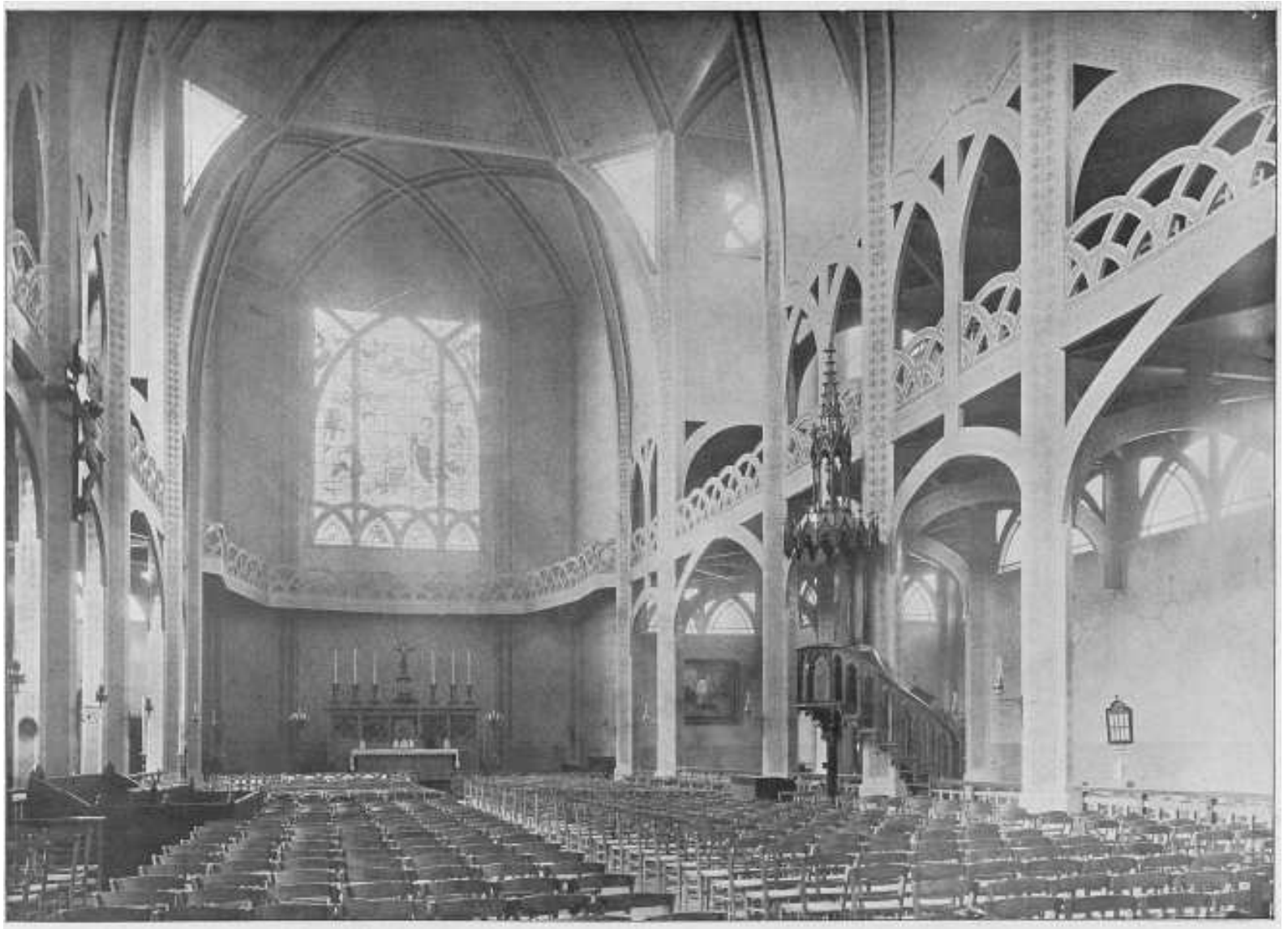


FIG. 3

The Royal Liver Building

Source : La Construction Moderne 1912(25), plate 98

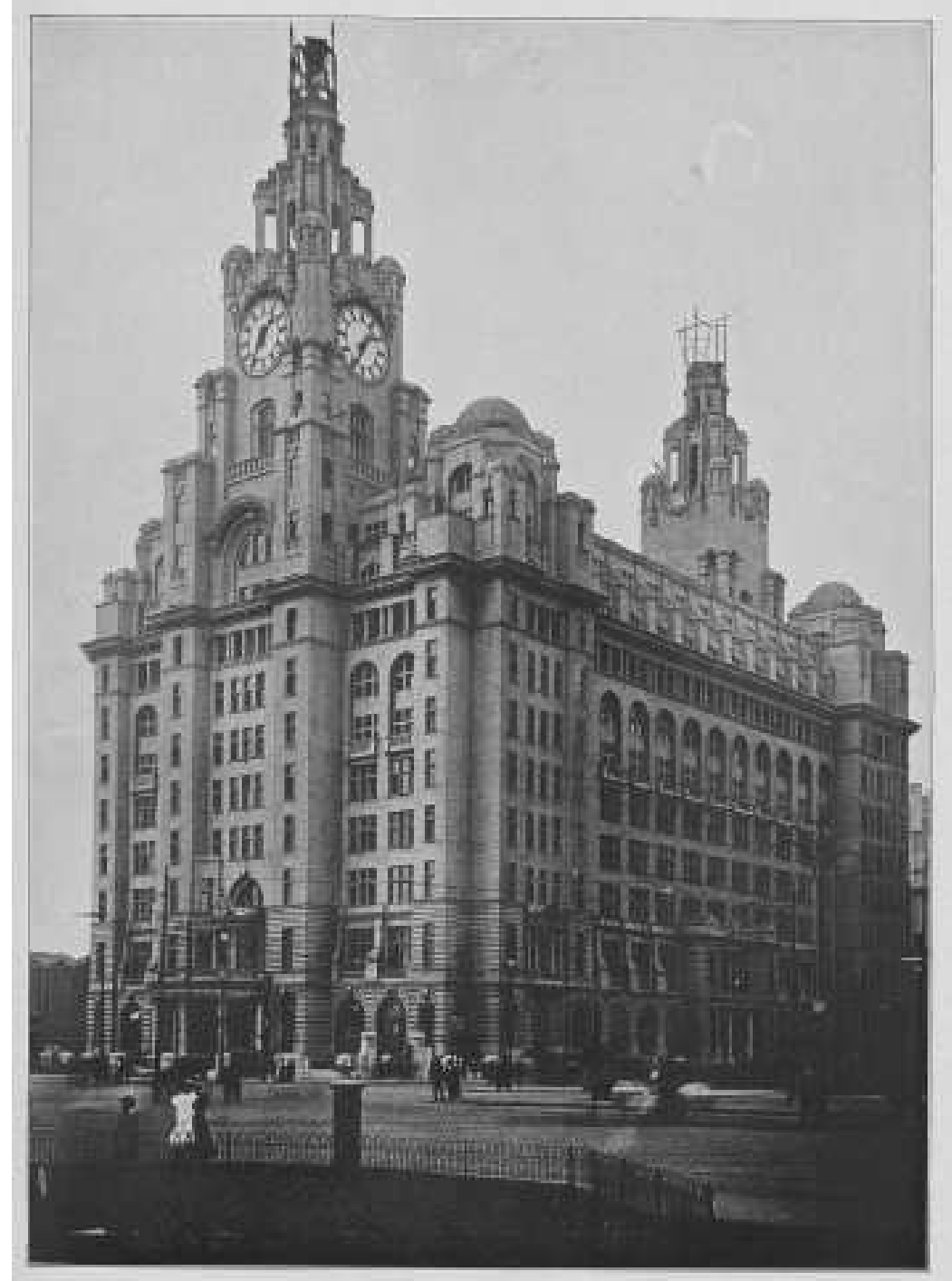

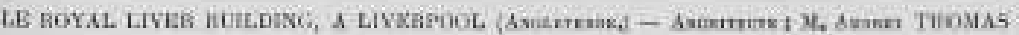


FIG. 4

Immeuble Ford

Source : La Construction Moderne 1931(24), plate 189

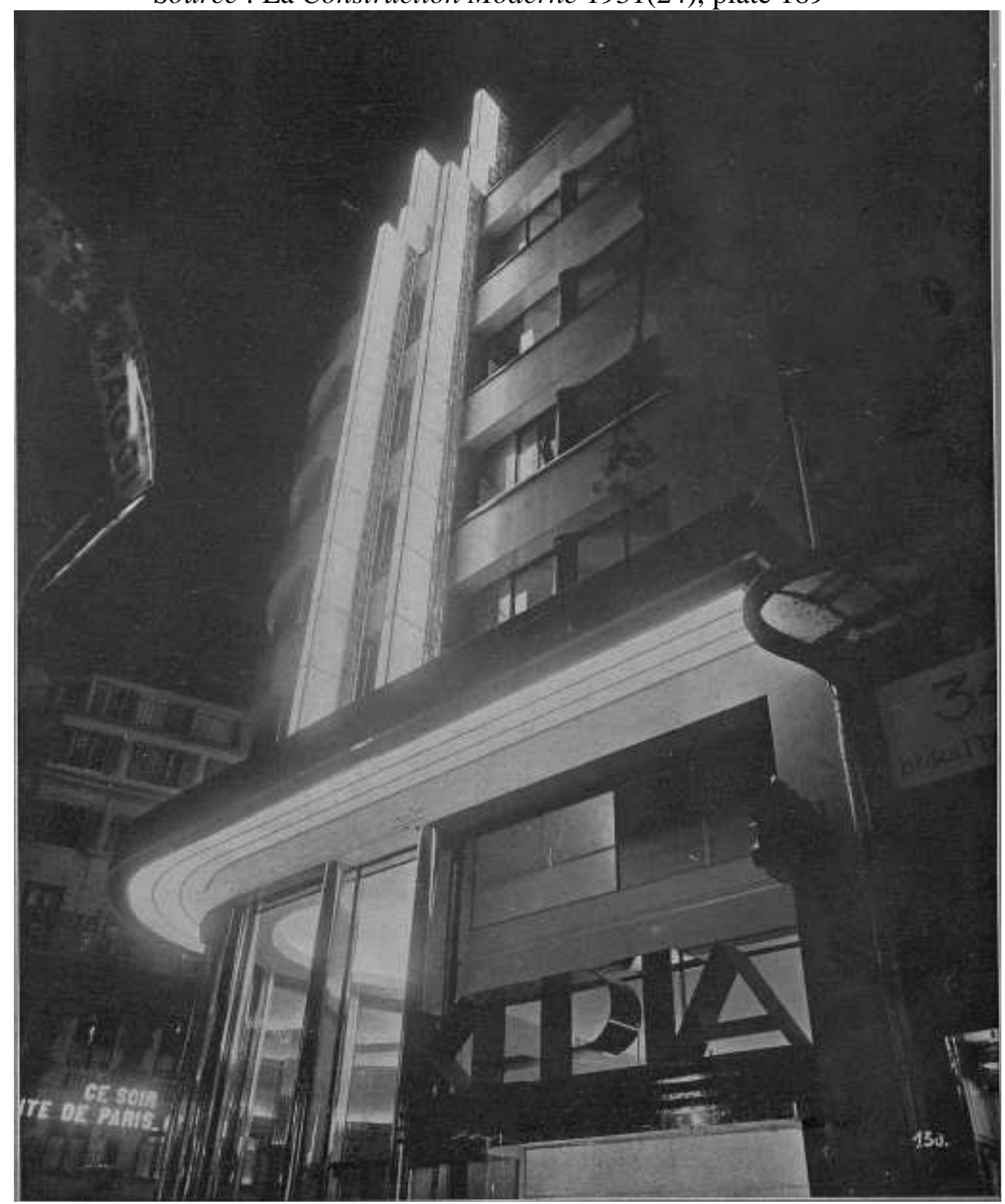


Fig. 5

Maison, 1 rue Danton

Source : La Construction Moderne 1901(15), plate 68

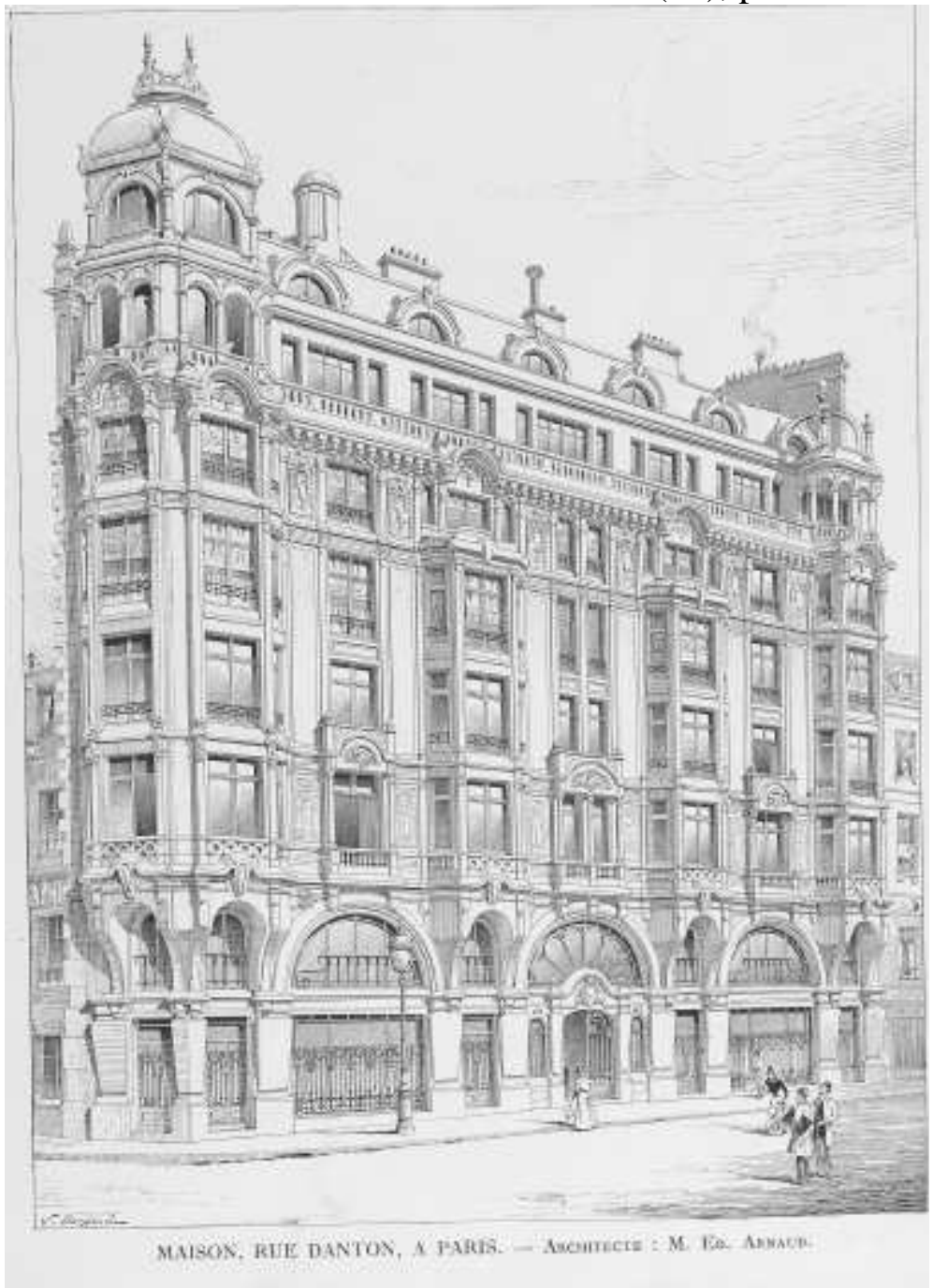


Fig. 6

Grand Hotel à Paris Plage

Source : La Construction Moderne 1929(20), plate 141

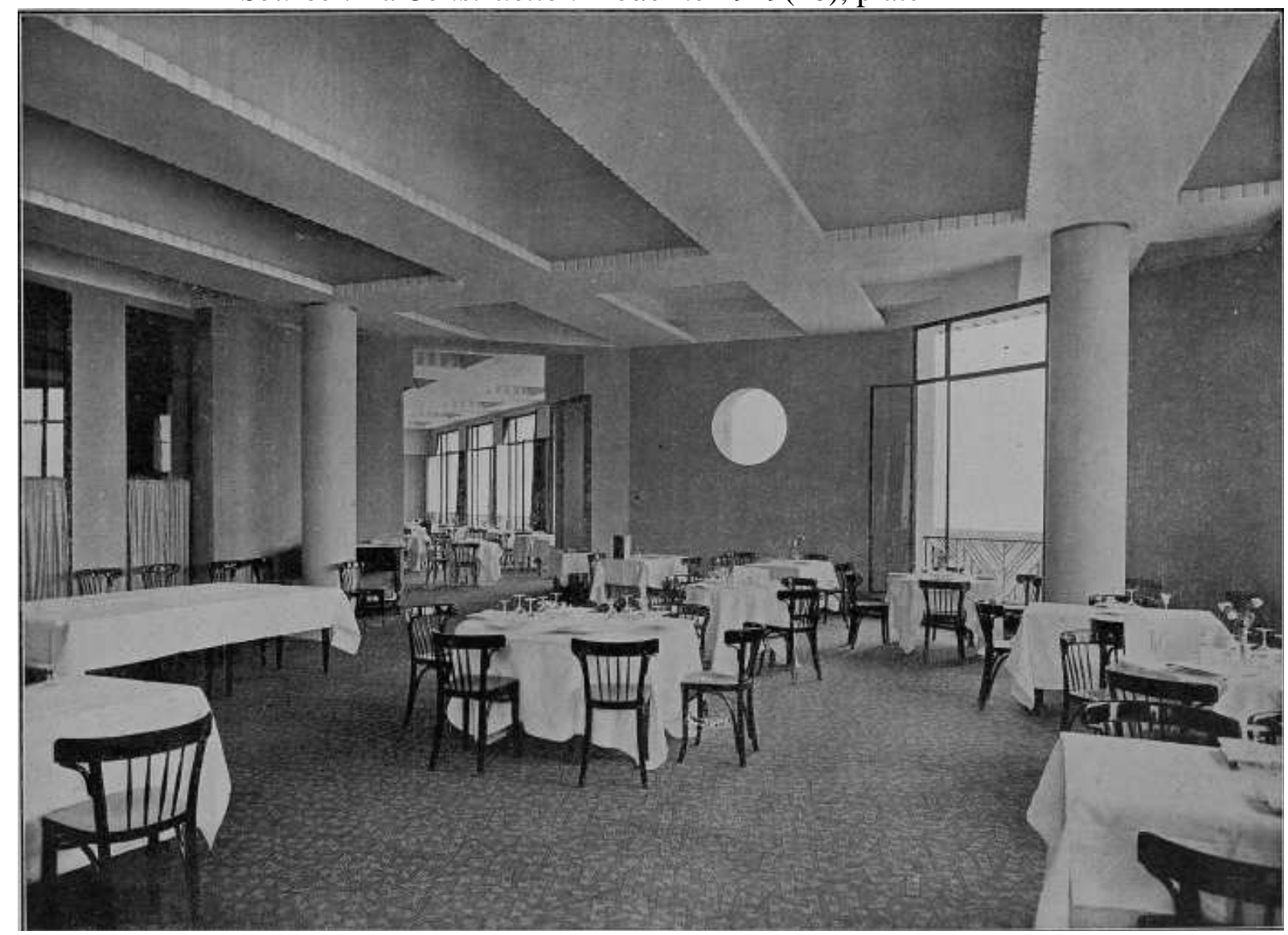


Fig. 7

Banque Nationale de Crédit à Nice

Source : La Construction Moderne 1929(24), plate 157

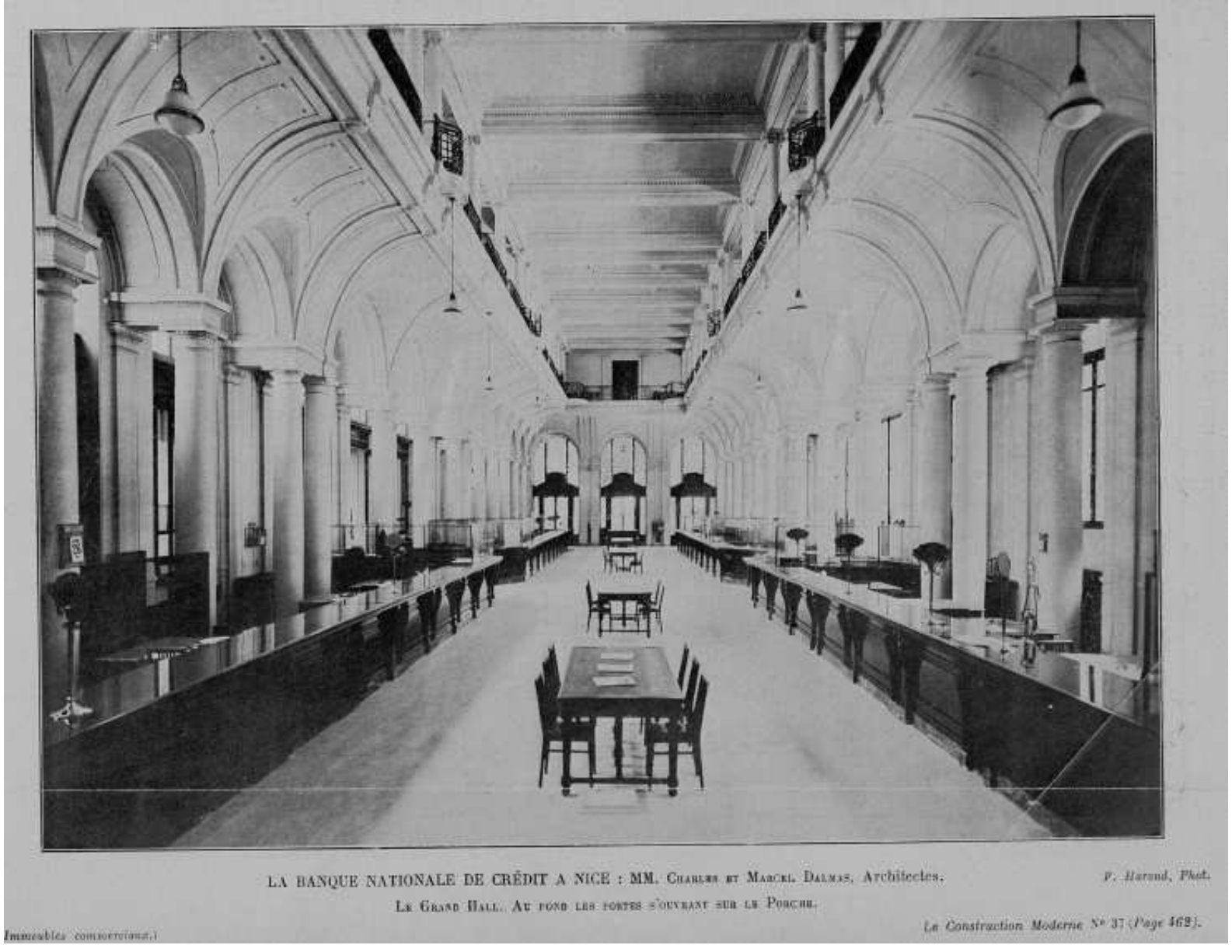


Fig. 8

Immeuble Ford

Source : La Construction Moderne 1931(24), plate 190

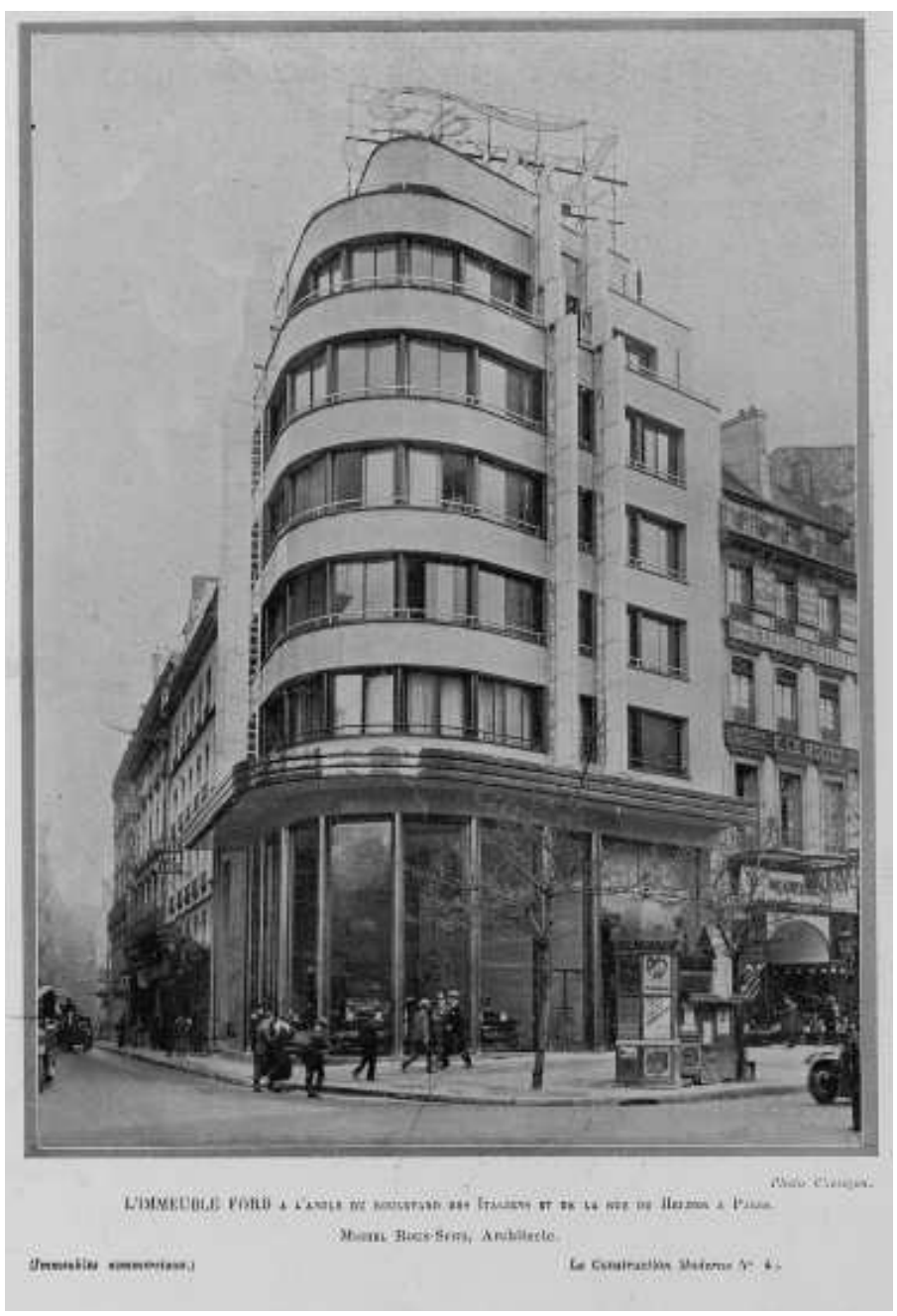


Fig. 9

Grand Hôtel à Paris Plage

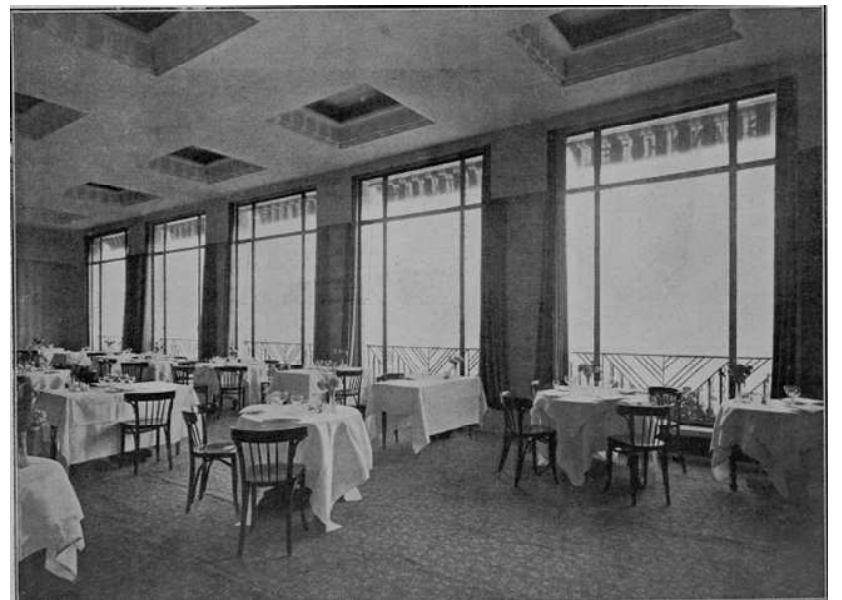

Plate 143 - CM 1929(20)

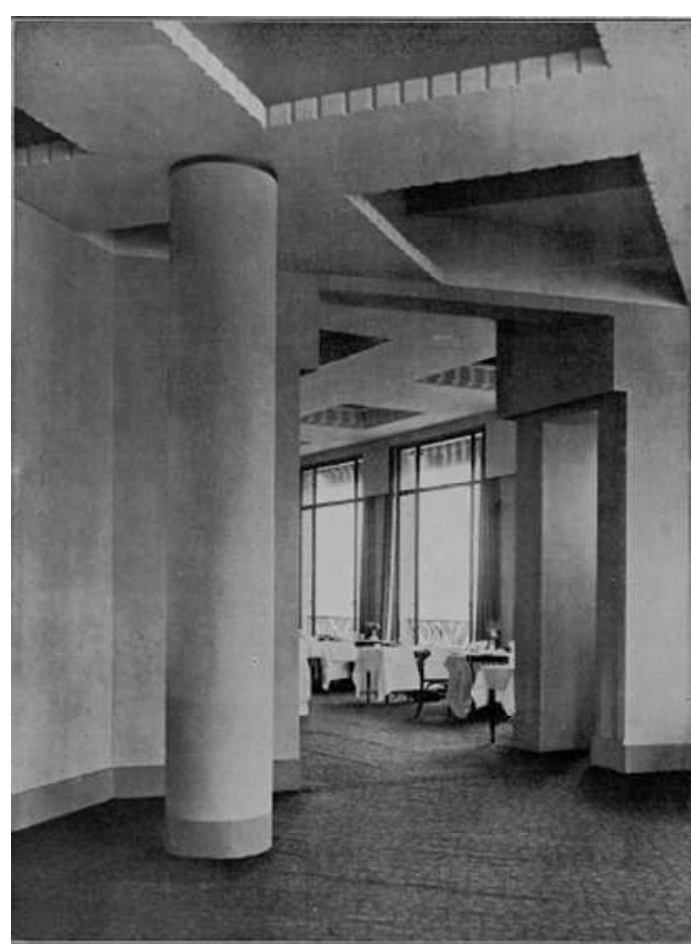

Plate 144 - CM 1929(20) 
Fig. 10

The role of dramatization and evaluation in the making of one causal chain

Field Level - Theorized causal chain

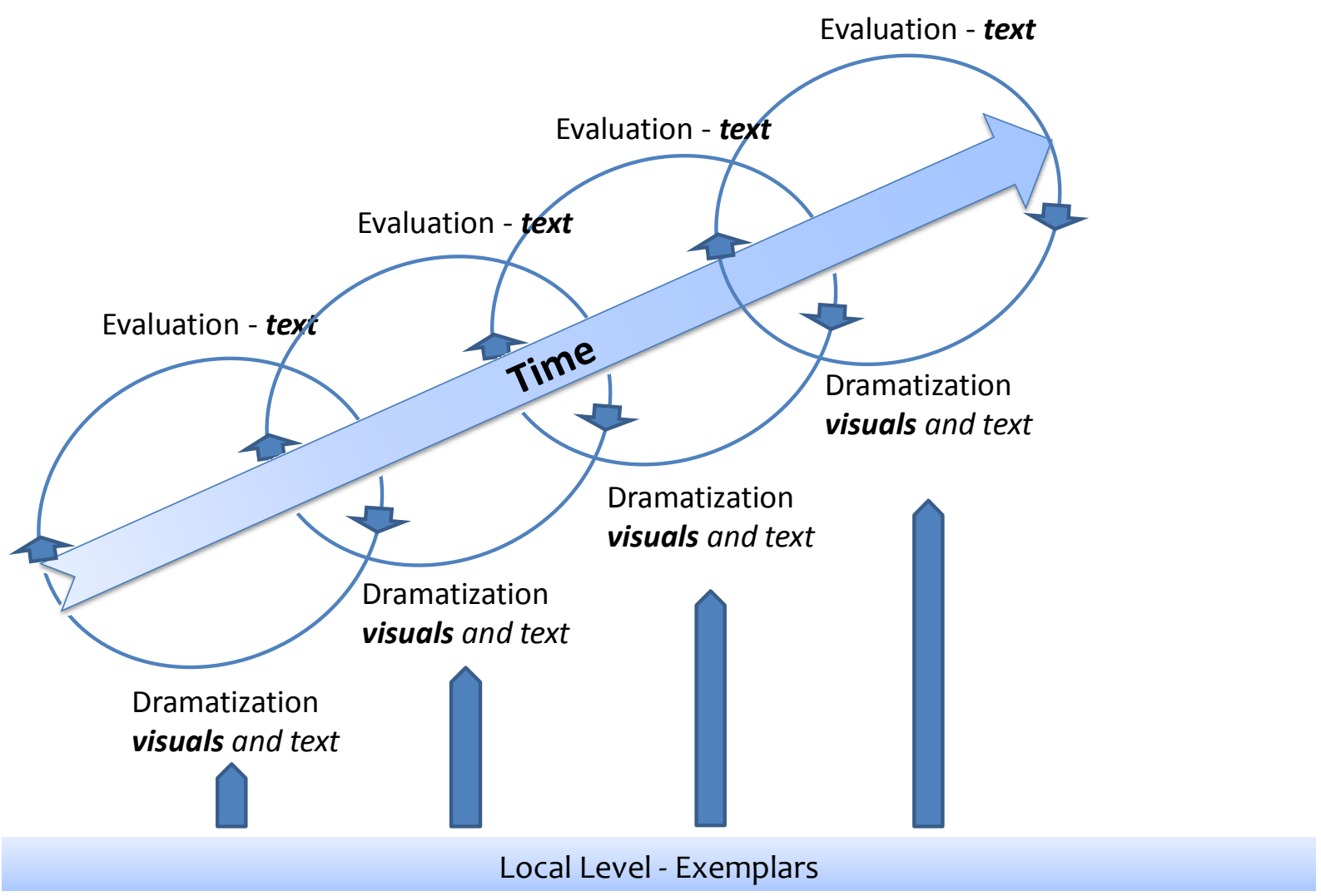




\section{APENDIX}

Table A.1

List of selected exemplars

\begin{tabular}{|c|c|}
\hline \multirow{5}{*}{$\frac{\text { Exemplar }}{\text { Pont Alexandre III }}$} & Associated articles \\
\hline & 1897(35)_6 \\
\hline & 1897(39)_2 \\
\hline & 1898(04)_7 \\
\hline & $1898(06)_{-}$ \\
\hline \multirow[t]{3}{*}{ Maison, 1 rue Danton } & 1901(15)_2 \\
\hline & 1901(16)_3 \\
\hline & 1901(18)_ \\
\hline \multirow[t]{3}{*}{ L'Eglise Saint Jean de Montmartre } & 1905(15)_3 \\
\hline & 1905(16)_3 \\
\hline & 1905(17)_2 \\
\hline Le Royal Liver Building & 1912(25)_5 \\
\hline \multirow[t]{2}{*}{ Canal de Panama } & 1913(35)_6 \\
\hline & 1913(35)_6 \\
\hline Grand Hôtel à Paris Plage & 1929(20)_1 \\
\hline Banque Nationale de Crédit à Nice & 1929(24)_02 \\
\hline L'immeuble Ford & 1931(35)_02 \\
\hline Villas d'Abraham & 1932(16)_01 \\
\hline $\begin{array}{ll}\text { Service } & \text { Technique }\end{array}$ & 1932(40)_02 \\
\hline Constructions Navales & \\
\hline Le village Sanatorium & 1933(11)_01 \\
\hline Le Lutecia & 1936(06)_02 \\
\hline
\end{tabular}


Table A.2

Sequence of events

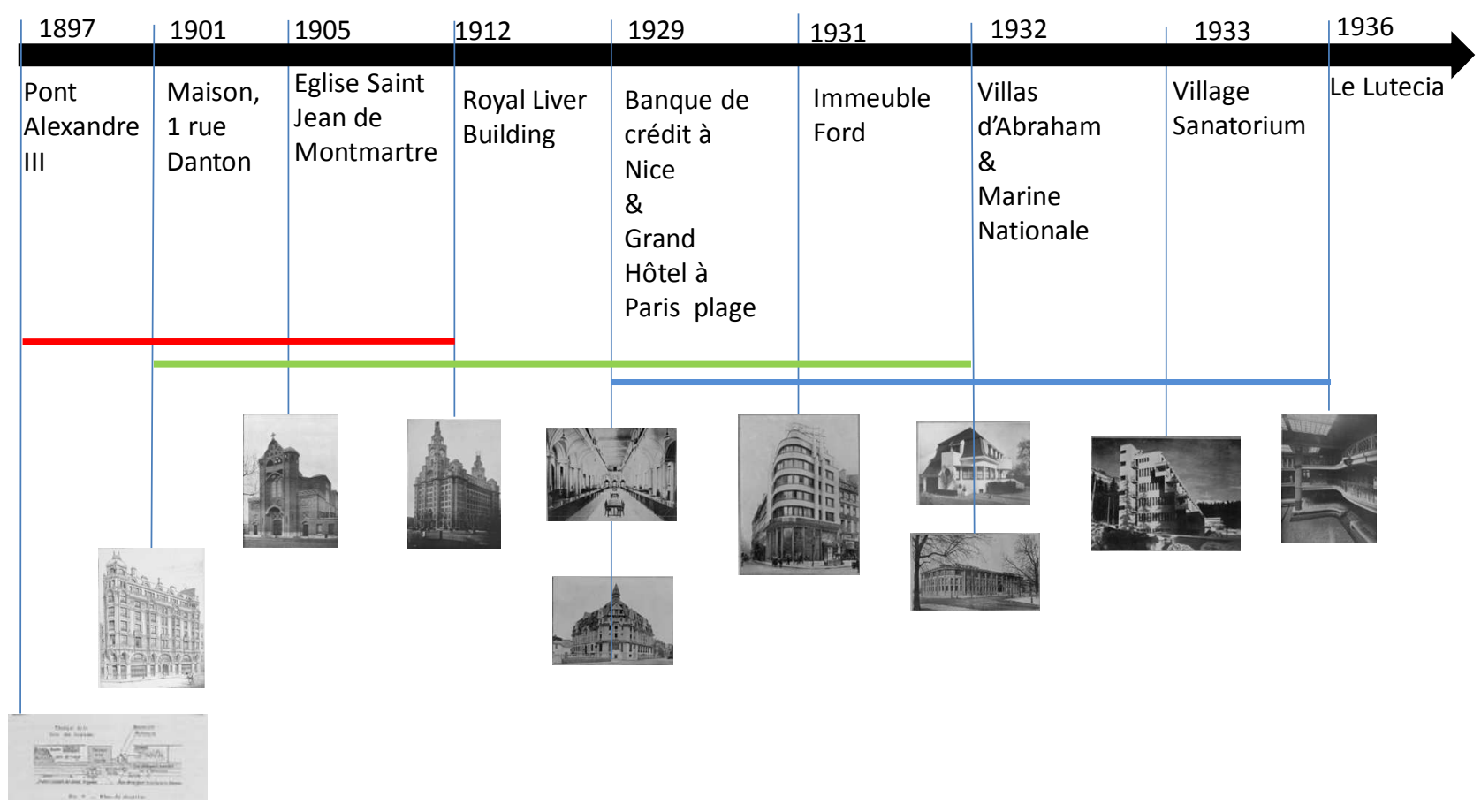

- Causal chain 1: Solidity Causal chain 2: Beauty

Causal chain 3: Flexibility 